\title{
Nobel laureate rejects drug company charges
}

Munich. Allegations that the Italian pharmaceutical company Fidia "bought" the 1986 Nobel prize for medicine for the Italian neuroscientist Rita Levi-Montalcini have provoked a rush of emotional denials from Italy's scientific community.

Levi-Montalcini was awarded the prize jointly with the US scientist Stanley Cohen for their work on nerve growth factors, carried out in the United States in the 1950s. She is widely revered in Italy as a symbol of scientific achievement and integrity.

The allegations have been made by Duilio Poggiolini, former head of the health ministry's pharmaceutical section, who was arrested last autumn on charges of soliciting and accepting bribes from pharmaceutical companies in exchange for the registration and 'suitable' pricing of their drugs (see Nature 364, 663; 1994).

The ring of corruption is claimed to have included health minister Francesco De Lorenzo, many leading industrialists from pharmaceutical companies, and academics who acted in 'advisory' capacities.

Poggiolini claims that Francesco della Valle, director of Fidia until 1991, told him that he had paid out 14 billion lire (US $\$ 8.4$ million) to assure the prize for LeviMontalcini. He says that part of the money was used to support her research, part to encourage other scientists to support her nomination, and part was given in bribes to the Nobel committee. Della Valle has denied the charge.

Nils Ringertz, general secretary of the
Karolinska Institute in Stockholm, whose Nobel Assembly awards the prize for medicine, says that its Nobel committee is not taking the allegations seriously. The procedure for selecting prizewinners is so long and complex, he says, that it would be impossible for pressure from any one source

\section{IMAGE UNAVAILABLE FOR COPYRIGHT REASONS} \& to be successful.

\section{Similarly Levi-} Montalcini herself has rejected the allegations against Fidia, claiming that the process for awarding Nobel prizes is "so complex that it cannot be corrupted".

Despite such as-

Levi-Montalcini: no basis to charges. surances, Italy is taking the affair very seriously. It is regarded as a blow to the country's scientific credibility, and one which could damage further a drug industry already on the verge of collapse in the wake of the drugs scandal.

Levi-Montalcini has received messages of support from all directions, including Italian president Oscar Luigi Scalfaro, Umberto Colombo, the minister of research, and many individual scientists. Colombo described the allegations as "slanderous", claiming that they are "denigrating to Italy's scientific community" and "seriously damaging to pharmaceutical concerns that are strongly committed to research and innovation".
The possible motivation behind Poggiolini's claims is difficult to guess. Levi-Montalcini is quoted in the Italian press as suggesting that multinational drug companies want to destroy the credibility of the entire Italian pharmaceutical industry to secure their own position in the Italian market. She claims that this theory has wide support, and also that the allegations are being used to discredit Italian science.

In a public statement, Colombo also hints at possible conspiracy. "One may wonder why accusations of this kind are being put about at just this critical juncture, when scientific research might provide the thrust needed to revitalize the nation's economy," he says darkly.

The allegations form part of a package of claims from Poggiolini, who is said to have maintained silence between his arrest last September and the end of January. He then implicated five executives from Italy's pharmaceutical companies in the drugs scandal, claiming that they had paid him bribes to assure the place - and price - of their drugs on the Italian market. Warrants against the five were issued last week, and four are already under arrest.

The four judges in Naples who are investigating the whole drugs scandal say in a joint statement that allegations that Fidia "bought" the Nobel prize are not central to their case. But they have not ruled out the possibility that they may seek permission to carry out investigations in Sweden at a future date.

Alison Abbott

\section{White House urged to build support for global projects}

San Francisco. The United States should ask the group of seven top economies (G7) to set up a panel to consider plans for major new international science facilities, and to recommend how these should be distributed between countries, according to Representative George Brown (Democrat, California).

The proposal is part of a three-stage plan to rescue the tarnished reputation of the United States as a reliable partner in international scientific collaborations, which Brown, who chairs the science, space and technology committee in the US House of Representatives, presented last Sunday (20 February), to the annual meeting of the American Association for the Advancement of Science (AAAS).

But the plan has a long way to go. "US government policies towards international collaboration are disastrous and incoherent," says Rodney Nichols of the New York Academy of Sciences. Tight budgets make that difficult to improve, he adds.

Brown said that the first step he is pro- posing is that Congress should prepare legislation to confirm its approval in principle of all proposed research projects worth more than $\$ 50$ million. This would not guarantee funding for such projects; but it would require Congress to commit itself clearly to a project in advance.

He also wants the president's science adviser to prepare a report summarizing all the big science projects requiring international collaboration up to the year 2010 . The president would then take this information to the G7.

Brown's staff have been investigating options for international collaboration in the wake of the collapse of the Superconducting Super Collider (SSC) and mounting concerns about the space station. He concedes that the last two proposals are vague, but says it would be up to the administration to provide the details.

"The only part we in Congress have control of is authorizing the big projects," he says. "The administration ought to be taking the lead on the other parts, and then asking Congress to assist with a framework of law to help them do what they need to do."

Brown and other key figures now say that several projects, such as the International Thermonuclear Experimental Reactor (see page 669), the Large Hadron Collider at CERN in Switzerland and a future linear collider for high-energy physics, must be considered jointly, with sites divided between the countries paying for them.

As the director of the Stanford Linear Accelerator Center, Burton Richter, told a AAAS symposium on the aftermath of the SSC: "We are not going to get them one at a time. If you decide on three projects at once, I think you'll have an easier task."

But Brown is not optimistic that the current administration will give the support needed to get any such projects off the ground. "Everything is in turmoil right now," he says. "If our national research and development effort continues to go downhill, we are not going to be in very good shape to talk about international collaboration on big science." 